CASE REPORT

\author{
J. Stevens \\ J.L. Leach \\ T. Abruzzo \\ B.V. Jones
}

\section{De Novo Cerebral Arteriovenous Malformation: Case Report and Literature Review}

SUMMARY: We describe a rare case of a de novo cerebral arteriovenous malformation (AVM) in a 9-year-old girl. MR imaging at 6 years of age demonstrated band heterotopia. Follow-up MR imaging 3 years later demonstrated a new 3.5-cm AVM in the left parietol-occipital region, confirmed by conventional angiography. This report, along with limited previous reports, suggests that AVMs can be acquired lesions and that AVM development is a dynamic process extending into the postnatal period.
A $\mathrm{n}$ arteriovenous malformation (AVM) is a vascular malformation characterized by arterio-venous shunt through a collection of tortuous vessels without an intervening capillary bed. ${ }^{1}$ The pathogenesis of AVMs is currently unknown. Although they are traditionally thought to be congenital in origin, with an initiating event occurring in early embryologic development, some have suggested a more dynamic developmental process. ${ }^{2,3} \mathrm{We}$ present a case of de novo AVM development in a region of the brain without abnormal vascularity on prior MR imaging and briefly review the literature on de novo AVM development and pathogenesis.

\section{Case Report}

A 6-year-old girl was evaluated with MR imaging because of seizures and developmental delay. Imaging demonstrated continuous band heterotopia (Fig 1A). No vascular abnormality or abnormal signal intensity was demonstrated.

Three years later the patient presented with increased seizure activity, behavioral changes, increased ataxia, and aphasia after a minor head injury. CT demonstrated no evidence of a skull fracture or hemorrhage. MR imaging (Fig $1 B$ ) revealed a tangle of serpiginous flow voids along the margin of the left lateral ventricle at the junction of the left temporal and occipital lobes, consistent with an AVM. Cerebral conventional angiography (Fig 2) delineated a 3.5-cm AVM nidus with predominant arterial supply from distal branches of the left middle and posterior cerebral arteries. Venous drainage was through the ipsilateral thalamostriate veins and also through parenchymal veins extending into the left transverse sinus. The patient is currently undergoing radiation therapy for this lesion.

\section{Discussion}

We present a rare example of de novo AVM formation in a child with abnormalities of neuronal migration. A literature review identified 5 previously reported cases of de novo AVM development. Three of these cases are of patients with preexisting vascular pathology who developed AVMs in or near pathologically altered brain. ${ }^{4-6}$ Only 2 previous reports ${ }^{7,8}$ document a cerebral AVM arising in brain parenchyma shown to be without vascular pathology on prior MR imaging. To our

\section{Received May 13, 2008; accepted June 16}

From the Department of Radiology (J.L.L., B.V.J.), Children's Hospital Medical Center, Cincinnati, Ohio; Department of Radiology, University of Cincinnati College of Medicine (J.S., J.L.L., T.A.), Cincinnati, Ohio; and The Neuroscience Institute (J.L.L., T.A.), Cincinnati, Ohio.

Paper previously presented at: Annual Meeting of the American Society of Neuroradiology, June 7-14, 2007; Chicago, III.

Please address correspondence to James L. Leach, MD, Cincinnati Children's Hospital Medical Center, 3333 Burnet Ave, Cincinnati, OH 45249; e-mail: james.leach@cchmc.org DOI 10.3174/ajnr.A1255 knowledge, no previously reported case has documented a de novo cerebral AVM developing in a patient with a neuronal migrational disorder.

The pathogenesis of AVMs is not completely understood and has largely been theorized. It has been suggested that cerebral AVMs are primarily congenital, originating at or before the 40- to 80 -mm embryo length stage and may be related to a primary abnormality of primordial capillary or venous formation. ${ }^{9}$ However, excluding Galenic fistulas, we have found few reports of confirmed cerebral AVMs diagnosed in utero, ${ }^{10}$ and they are much more commonly diagnosed in adults than in children, challenging the assumption that all AVMs are congenital. Other concepts of cerebral AVM pathogenesis focus on the potential temporal vulnerability of susceptible vascular cellular elements to a physiologic trigger. This trigger could be mechanical, hormonal, thrombotic, hemodynamic, thermal, ischemic/hypoxemic, or inflammatory in nature. ${ }^{11,12}$

Vascular endothelial growth factor (VEGF) may be 1 link between insult and AVM formation. One study demonstrated significantly higher levels of VEGF in patients with AVMs compared with a control group. ${ }^{13}$ Patients with hereditary hemorrhagic telangiectasia (HHT) have an increased prevalence of AVMs and also have elevated levels of VEGF. ${ }^{14,15}$ Hypoxia is known to stimulate expression of VEGF. Hemorrhage and thrombogenesis can result in the release of VEGF from platelets. Infection can lead to the release of VEGF at the source of infection. Thus, in theory, insults such as stroke, brain contusion, and encephalitis could all potentially promote the development of AVMs. ${ }^{16}$

Cerebral AVMs are not static lesions: Growth and shrinkage of AVMs with time have been documented. ${ }^{17,18}$ Several cases of AVM recurrence in the same location following some form of intervention (ie, gamma knife, excision, embolization, etc) have been reported in pediatric patients and adults. ${ }^{19,20}$

Abnormalities of arterial ${ }^{21}$ venous, ${ }^{22}$ and microvascular ${ }^{23}$ structures have been described in relation to areas of abnormal neuronal migration. Abnormal vascular structures have been described in association with periventricular nodular heterotopia in filamin 1 gene mutation, ${ }^{23}$ suggesting 1 potential link between neuronal migrational disorders and vascular malformations.

\section{Conclusions}

This case report demonstrates postnatal development of an arteriovenous malformation in a patient with extensive band heterotopia. This case and the few previous reports of de novo AVM challenge the concept that cerebral AVMs are purely congenital lesions. AVMs appear to be dynamic lesions that 

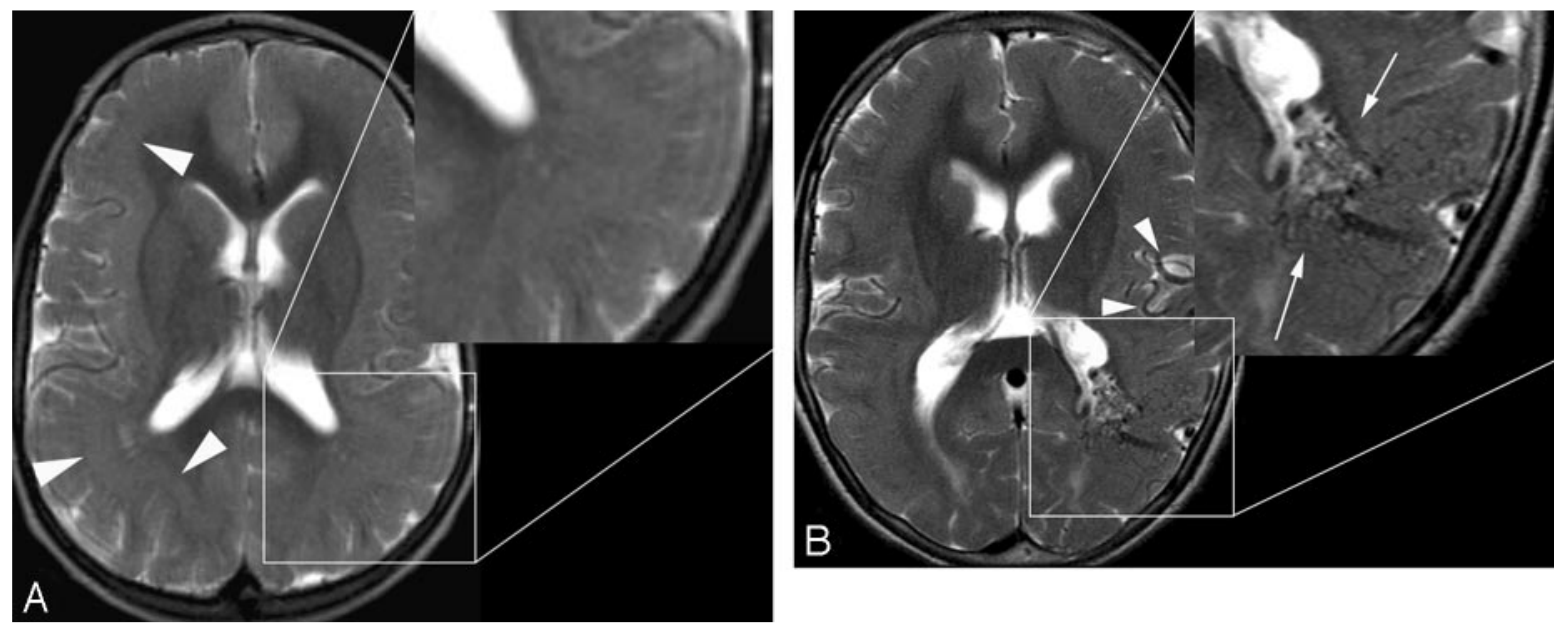

Fig 1. A, Axial T2-weighted MR imaging at 6 years of age demonstrates diffuse band heterotopia (arrowheads). Note the absence of enlarged vessels in the magnified segment. B, Axial T2-weighted image at the same level 3 years later demonstrates a new serpiginous grouping of signal-intensity voids in the left parieto-occipital region along the margin of the left lateral ventricle consistent with an AVM (arrow). Enlarged left middle cerebral artery feeding vessels are also noted (arrowheads).

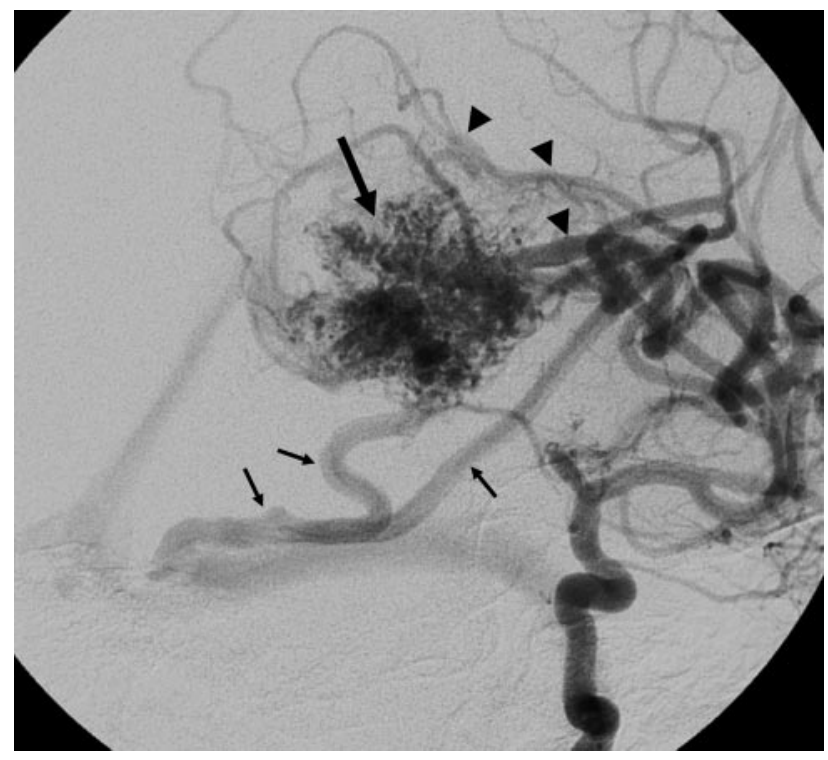

Fig 2. Oblique projection of a left internal carotid angiogram shows a 3.5-cm left parietooccipital AVM nidus (large arrow) supplied by parietal middle cerebral artery branches (arrowheads), with venous drainage primarily to the medial transverse sinus near the torcular (small arrows). Additional deep venous drainage is not as well seen on this projection.

have the potential to develop and grow with time. It is possible that acquired insults can provide the catalyst for the formation of AVMs later in life, and as suggested by this case, disorders of neuronal migration may share common genetic ground with abnormalities of endothelial proliferation.

\section{References}

1. Fleetwood IG, Steinber GK. Arteriovenous malformations. Lancet 2002;359:863-73

2. Stapf C, Mohr JP. New concepts in adult brain arteriovenous malformations. Curr Opin Neurol 2000;13:63-67

3. Nussbaum ES, Heros RC, Madison MT, et al. The pathogenesis of arteriovenous malformations: insights provided by a case of multiple arteriovenous malformations developing in relation to a developmental venous anomaly. Neurosurgery 1998;43:347-51

4. Schmit BP, Burrows PE, Kuban K, et al. Acquired cerebral arteriovenous malformation in a child with Moyamoya disease: case report. J Neurosurg 1996;84:677-80

5. Rodriquez-Arias C, Martinez R, Rey G, et al. Recurrence in a different location of a cerebral arteriovenous malformation in a child after radiosurgery. Childs Nerv Syst 2000;16:363-65

6. Song JK, Niimi Y, Kupersmith MJ, et al. Postnatal growth and development of a cerebral arteriovenous malformation on serial magnetic resonance imaging in a child with hemangiomatosis. J Neurosurg 2007;106 (suppl 5):384-87

7. Gonzalez LF, Bristol RE, Porter RW, et al. De novo presentation of an arteriovenous malformation: case report. J Neurosurg 2005;102:726-29

8. Bulsara KR, Alesander MJ, Villavicencio AT, et al. De novo cerebral arteriovenous malformation: case report. Neurosurgery 2002;50:1137-41

9. Mullan S, Mojtahedi S, Johnson DL, et al. Embryological basis of some aspects of cerebral vascular fistulas and malformations. J Neurosurg 1996:85;1-8

10. DeCesare B, Omojola MF, Fogarty EF, et al. Spontaneous thrombosis of congenital cerebral arteriovenous malformation complicated by subdural collection: in utero detection with disappearance in infancy. $\mathrm{Br} J$ Radiol 2006;79:e140-44

11. Lasjaunias PL. Vascular Diseases in Neonates, Infants, and Children: Interventional Neuroradiology Management. Berlin, Germany: Springer-Verlag; 1997:51-65

12. Yasargil MG. Pathological considerations. In Yasargil MG, ed Microneurosurgery: AVM of the Brain, History, Embryology, Pathological Considerations, Hemodynamics, Diagnostic Studies, Microsurgical Anatomy. New York: Thieme Verlag; 1987:49-211

13. Sandalcioglu IE, Wende D, Eggert A, et al. Vascular endothelial growth factor plasma levels are significantly elevated in patients with cerebral arteriovenous malformations. Cerebrovasc Dis 2006;21:154-58

14. Du R, Hashimoto T, Tihan T, et al. Growth and regression of arteriovenous malformations in a patient with hereditary hemorrhagic telangiectasia. $\mathrm{JNeu}$ rosurg 2007;106:470-77

15. Matsubara S, Manzia JL, ter Brugge K, et al. Angiographic and clinical characteristics of patients with cerebral arteriovenous malformations associated with hereditary hemorrhagic telangiectasia. AJNR Am J Neuroradiol 2000;21:1016-20

16. Sure U, Butz N, Schlegel J, et al. Endothelial proliferation, neoangiogenesis, and potential de novo generation of cerebrovascular malformations. J Neurosurg 2001;94:972-77

17. Ezura M, Kagawa S. Spontaneous disappearance of a huge cerebral arteriovenous malformation: case report. Neurosurgery 1992;30:595-99

18. Minakawa T, Tanaka R, Koike T, et al. Angiographic follow-up study of cerebral arteriovenous malformations with reference to their enlargement and regression. Neurosurgery 1989;24:68-74

19. Gabriel EM, Sampson JH, Wilkins RH. Recurrence of a cerebral arteriovenous malformation after surgical excision: case report. J Neurosurg 1996;84:879-82

20. Kader A, Goodrich JT, Sonstein WJ, et al. Recurrent cerebral arteriovenous malformations after negative postoperative angiograms. J Neurosurg 1996;85:14-18

21. Abe T, Singer R, Marks M, et al. Arterial vascular abnormality accompanying cerebral cortical dysplasia. AJNR Am J Neuroradiol 1997;18:144-46

22. Barkovich AJ. Abnormal vascular drainage in anomalies of neuronal migration. AJNR Am J Neuroradiol 1988;9:939-42

23. Kakita A, Hayashi S, Moro F, et al. Bilateral periventricular nodular heterotopia due to filamin 1 gene mutation: widespread glomeruloid microvascular anomaly and dysplastic cytoarchitecture in the cerebral cortex. Acta Neuropathol 2002:104;649-657. Epub 2002 Jul 23 